\title{
Race and food store availability in an inner-city neighbourhood
}

\author{
Maida P Galvez ${ }^{1,2, *}$, Kimberly Morland' ${ }^{1}$ Cherita Raines $^{3}$, Jessica Kobil ${ }^{3}$, \\ Jodi Siskind ${ }^{1}$, James Godbold ${ }^{1}$ and Barbara Brenner ${ }^{1}$ \\ 'Department of Community and Preventive Medicine, Mount Sinai School of Medicine, 1 Gustave L Levy Place \\ Box 1512, New York, NY 10029, USA: ${ }^{2}$ Department of Pediatrics, Mount Sinai School of Medicine, New York, \\ NY, USA: ${ }^{3}$ Mount Sinai School of Medicine, New York, NY, USA
}

Submitted 7 February 2007: Accepted 23 July 2007: First published online 15 0ctober 2007

\begin{abstract}
Background: A growing body of research has shown that disparities in resources, including food stores, exist at the neighbourhood level and the greatest disparities are seen in minority neighbourhoods, the same neighbourhoods at increased risk of obesity and diabetes. Less is known about whether differences in availability of resources by African American or Latino race/ethnicity exist within a single minority community.

Objective: The present study examined whether census blocks either $75 \%$ African American (AA) or 75\% Latino (L) are associated with food store availability, as compared with racially mixed (RM) census blocks, in East Harlem, New York. Design/methods: A cross-sectional study utilising a walking survey of East Harlem was performed. Food stores were classified into: supermarkets, grocery stores, convenience stores, specialty stores, full-service restaurants and fast-food stores. Results: One hundred and sixty-five East Harlem census blocks were examined; 17 were AA, 34 were L and 114 were RM. Of AA census blocks, 100\% had neither supermarkets nor grocery stores. AA census blocks were less likely to have convenience stores (prevalence ratio $(\mathrm{PR})=0.25,95 \%$ confidence interval (CI) 0.07-0.86) compared with RM census blocks. In contrast, predominantly L census blocks were more likely to have convenience stores ( $\mathrm{PR}=1.8,95 \%$ CI 1.20-2.70), specialty food stores ( $\mathrm{PR}=3.74,95 \%$ CI 2.06-7.15), full-service restaurants $(\mathrm{PR}=1.87,95 \% \mathrm{CI} 1.04-3.38)$ and fast-food restaurants $(\mathrm{PR}=2.14,95 \% \mathrm{CI}$ 1.33-3.44) compared with RM census blocks.

Conclusions: We found that inequities in food store availability exist by race/ ethnicity in East Harlem, New York. This has implications for racial/ethnic differences in dietary quality, obesity and obesity-related disorders.
\end{abstract}

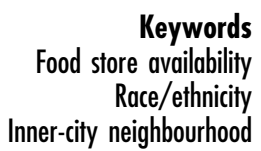

The fundamental cause of the rising obesity epidemic is an imbalance between energy intake and energy expenditure $^{1,2}$. It is well documented that minority communities, specifically African Americans and Latinos, are at high risk for obesity and its sequelae, and that lowincome neighbourhoods are at high risk ${ }^{1,3}$. But what role does neighbourhood play in this epidemic? A growing body of research is examining dietary quality and risk for obesity as it relates to the local food environment, defined as the physical availability of food stores ${ }^{4-10}$. Identifying key differences in the local food environment may help address the racial, ethnic and socio-economic disparities in obesity-related health outcomes including diabetes, cardiovascular health and mental health, to name a few $^{11-13}$.

Much like disparities seen in certain health outcomes, often the most striking contrasts in the local food envir- onment are seen between low-income, minority communities and more affluent, predominantly Caucasian neighbourhoods ${ }^{14-16}$. In an assessment of the prevalence of supermarkets by neighbourhood wealth and race, Morland et al. found four times fewer supermarkets located in African American neighbourhoods than in Caucasian neighbourhoods ${ }^{17}$. In another report, zip codes with higher proportions of African Americans were found to have substantially fewer chain supermarkets available and this relationship remained significant even when adjusted for neighbourhood income ${ }^{18}$. Studies from the USA to Scotland, England and Australia have shown that low-income neighbourhoods have a higher density of unhealthy food sources, specifically fast-food restaurants $^{19-21}$. A study conducted in New Orleans, Louisiana reported that predominantly black neighbourhoods have 2.4 fast-food restaurants per square mile compared with 
1.5 fast-food restaurants in predominantly white neighbourhoods $^{19}$. Similarly, it has been shown that poorer areas and non-Caucasian areas also have fewer fruit and vegetable markets, bakeries, specialty stores and natural food stores ${ }^{16}$.

A basic understanding of the local food environment is necessary for physicians and public health officials to fully comprehend the supports and barriers that exist to leading a healthy lifestyle in the communities they serve, a critical first step in combating the obesity epidemic. A recent study conducted by Horowitz et al. documented the lack of availability of foods recommended for people with diabetes in East Harlem, New York compared with availability in the Upper East Side, an adjacent, more affluent and predominantly Caucasian neighbourhood ${ }^{22}$. Based on this study it was reported that East Harlem has fewer large food stores and fewer stores that carry recommended food items; residents live with far more undesirable stores close to their homes than residents of the Upper East Side. Only 18\% of East Harlem stores carried all five recommended food items, as compared with 58\% of Upper East Side stores. This overwhelming exposure to stores with limited stocks of fresh, healthy foods has been referred to as a 'toxic food environment $^{23}$. The implications of this include the need to address factors in the local food environment at both the individual level, when recommending dietary changes, and the community level, when addressing deficiencies in the local food environment.

Clearly, inequities by neighbourhood exist in the types of food stores that are available. Why is this important? Food store availability alone has been associated with improved access to heart-healthy foods and ultimately improved dietary quality. In one study, supermarkets had two times the amount of heart-healthy foods (described as low-fat and low-sodium) than neighbourhood grocery stores and four times the number of these foods than convenience stores ${ }^{24}$. Moreover, the presence of a single supermarket within a census tract was associated with a $32 \%$ increase in fruit and vegetable intake ${ }^{25}$. Dietary quality influences risk for obesity, suggesting that food store availability may play a role in the aetiology of obesity. Morland et al. reported that while availability of supermarkets is associated with decreased prevalence of overweight and obesity, the availability of grocery stores and convenience stores is associated with an increased prevalence of overweight and obesity ${ }^{26}$.

Interventions targeting the local food environment have been shown to influence dietary intake. After provision of a large-scale retail store in Leeds, England, access to fresh, healthy food choices increased significantly and there was a corresponding increase in fruit and vegetable consumption ${ }^{27}$. Hence, the local food environment may influence dietary intake and together these factors may prove to be an important determinant for obesity.
The growing body of evidence thus suggests that food stores, and more specifically racial/ethnic differences in food store availability, are an important area to examine with respect to furthering our understanding of racial disparities in the obesity epidemic. While disparities in food store availability of African American neighbourhoods as compared with Caucasian neighbourhoods have been examined, less is known about the food store availability of predominantly Latino areas. Thus the present study examined whether census blocks of predominantly one race (African American or Latino census blocks) were associated with the availability of food stores, specifically supermarkets, grocery stores, convenience stores, specialty stores, full-service restaurants and fast-food restaurants. This information could prove useful in understanding the racial/ethnic differences in dietary quality and subsequent risk for obesity.

\section{Methods}

\section{Census blocks}

The unit for analysis for this study was the census block, the smallest defined geographic area available. New York City census blocks in general correspond to individual city blocks bounded by streets. This geographic area was utilised because we were interested in describing the food environment in closest proximity and thus most conveniently located to where a person resides.

East Harlem is located in the north-east corner of Manhattan, north of 96th Street, east of Fifth Avenue, and bounded by the Harlem River on the northern and eastern border (see Fig. 1 below). We studied the two East Harlem zip codes 10029 and 10035, where there are 248 census blocks. Of the 248 census blocks located in these two zip codes, 165 were included in these analyses. Eighty-three census blocks with no population (total population $=0$ ) were excluded from analysis because no race/ethnicity data could be obtained for these areas.

Census 2000 variables on racial demographics were downloaded in order to categorise census blocks as $>75 \%$ African American (AA), $>75 \%$ Latino (L) or racially mixed (RM). If blocks were neither African American nor Latino, they were considered racially mixed, i.e. there was no single ethnic group that was predominant in those blocks. Only three census blocks that were $>75 \%$ predominantly Caucasian (Census 2000) were grouped with the racially mixed blocks for analysis.

Population density (total population/geographical area) was calculated by extracting data on total population and geographical area for each census block. Median income and median rent were extracted from Census 2000 as a measure of neighbourhood wealth. Since these data were available only at the level of census block group (the next largest geographical area to the census block), median income and median rent were imputed 
for census blocks based on racial composition and incomes for corresponding census block groups (see Statistical analysis).

\section{Measurement of the local food environment}

A comprehensive block-by-block walking survey of East Harlem zip codes 10029 and 10035 was performed in 2004 by a single surveyor. Of the 405 food stores/food service restaurants surveyed by walking, 99.98\% were geocoded to blocks using ArcGIS 8.3.

Using codes from the 2002 North American Industry Classification System ${ }^{17}$, food stores are defined as industries that retail food and beverage merchandise from fixed point-of-sale locations. Food stores were classified into the following categories based on the number of cash registers and what was sold: supermarkets (four or more cash registers), grocery stores (two or three cash registers), convenience stores (stores with one cash register commonly referred to as bodegas or tienditas in East Harlem) and specialty stores (stores selling primarily one type of food item, e.g. fruit market, ice cream shop, bakery). We also surveyed full-service restaurants and fast-food stores, both local and national chains. As we collected information only on stores from fixed point-ofsales locations, transient sources such as mobile food vendors were not included.

\section{Independent variables}

Neighbourhood wealth as measured by median income and median rent at the block group level was considered as a possible confounding variable, and therefore needed to be included in the statistical model. Socio-economic variables of median income and median rent were available at the block group level, but not at the census block level. Therefore, multiple imputation methods were used to generate imputed values for income and rent at the census block level ${ }^{28}$. This imputation was accomplished by concatenating the dataset for block group (which contained variables on race, median income and rent) and the dataset for block (which contained only the variable race). Using the economic variables available at the block group level, a model predicting median income and median rent was used to impute values for the economic variables at the census block level. The imputed values at the census block level were used in the multivariate Poisson regression model. Because the imputed socio-economic status variables were highly correlated, only median household income was used as a covariate.

\section{Dependent variables}

Food stores and restaurants were measured as individual counts $(0,1,2, \ldots, x)$. Models were run separately for each type of food store/restaurant.

\section{Statistical analysis}

Multivariate Poisson regression analysis was used to examine the association between the number of food stores and block racial composition ${ }^{29}$. Prevalence ratios (PRs) and 95\% confidence interval (CIs) were calculated for each type of food store adjusting for block-level median household income and population density. Substituting median gross rent for median income did not significantly affect the prevalence ratios. To adjust for overdispersion, Poisson models included a scale parameter estimated by deviance divided by the degrees of freedom. Indicator variables were created for each racial category previously described, with racially mixed as the reference. All analyses were performed in SAS version 9.1.3 (SAS Institute) using the GENMOD procedure.

\section{Results}

Figure 1 illustrates the East Harlem census blocks by race/ ethnicity and all food resources (food store and restaurant locations) within East Harlem. Of the 165 East Harlem census blocks that we examined, 17 were $>75 \%$ AA, 34 were $>75 \% \mathrm{~L}$ and 114 were RM. East Harlem census blocks are clustered by racial characteristics as illustrated in Fig. 1. Even in an already segregated city such as New York, East Harlem itself is racially segregated. For example, $99 \%$ of AA census blocks were located adjacent to another predominantly AA census block. Food stores and restaurants are depicted in their respective locations.

Table 1 illustrates the demographics of the East Harlem census blocks that were included for analysis as defined by racial/ethnic predominance. This includes the mean population, area, population density (persons/sq km), median gross rent and median household income of the census blocks that were identified as predominantly AA, L and RM, and all East Harlem census blocks. The total population of East Harlem, according to the 2000 Census, was 117743 of whom 88\% were Hispanic or African American. Compared with the population density of AA census blocks, L blocks are 50\% more dense and RM blocks are 2.5 times as dense in population. As noted in Table $1,76 \%$ of the AA census blocks had no food stores present. In contrast, $15 \%$ of L census blocks and $40 \%$ of the RM census blocks had no food stores.

Table 2 describes income- and population densityadjusted PRs for food store availability by racial composition of the census block. In 2004, the local food environment of East Harlem, New York consisted of 405 food stores and food service places including nine supermarkets, eight grocery stores, 168 convenience stores, 34 specialty stores, 56 full-service restaurants and 130 fast-food restaurants (see Table 2). Of note, convenience stores were the predominant food store type in East Harlem. 


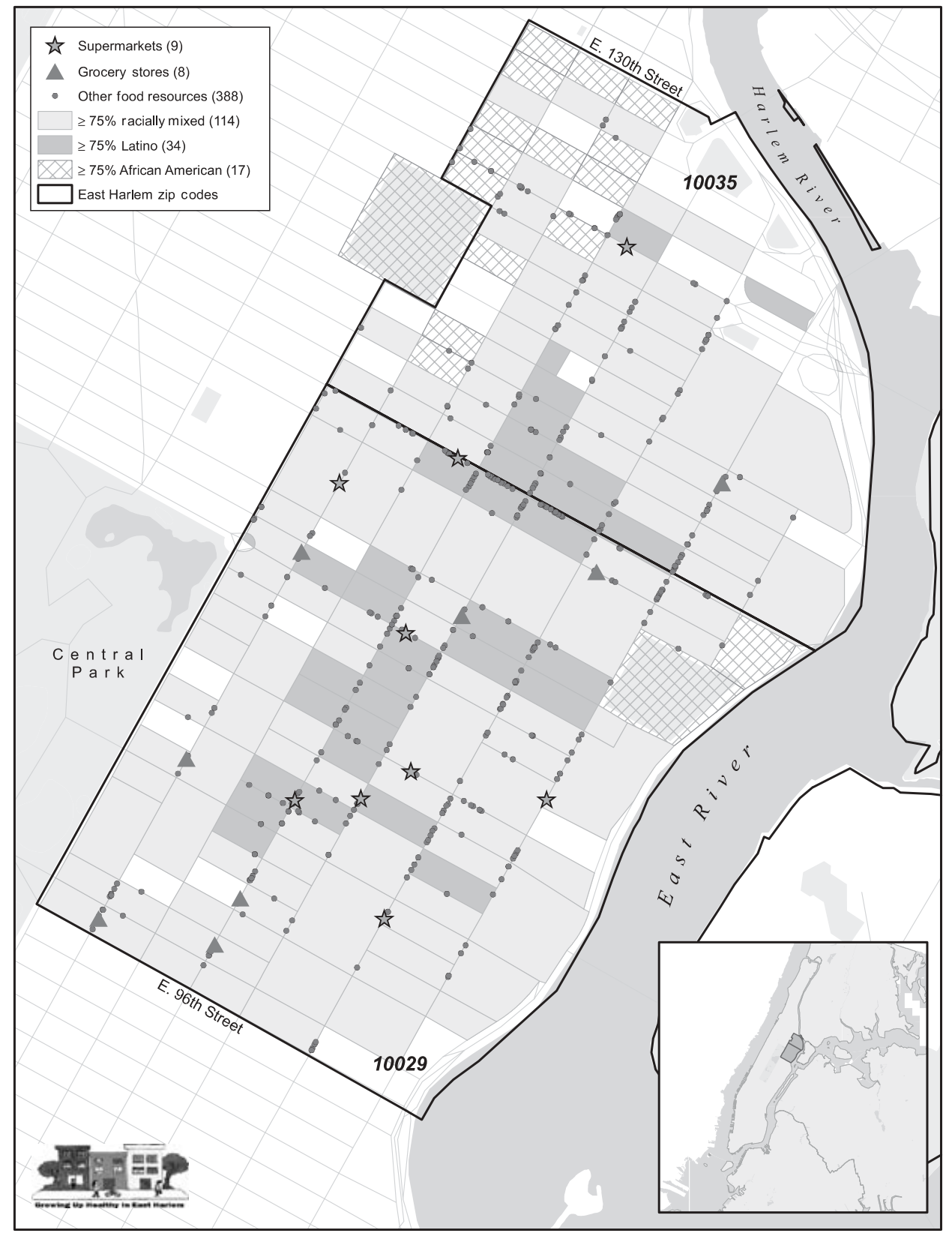

Fig. 1 East Harlem census blocks by race and food resources (food stores and restaurants)

As seen in Table 2, 100\% of AA census blocks had neither supermarkets nor grocery stores. Predominantly AA census blocks were less likely to have convenience stores ( $\mathrm{PR}=0.25,95 \% \mathrm{CI}$ 0.07-0.86) as compared with RM census blocks. In contrast, predominantly L census blocks were more likely to have convenience stores ( $\mathrm{PR}=1.80,95 \%$ CI $1.20-2.70)$, specialty food stores ( $\mathrm{PR}=3.74,95 \%$ CI 2.06-7.15), full-service restaurants $(\mathrm{PR}=1.87,95 \% \mathrm{CI}$ 1.04-3.38) and fast-food restaurants $(\mathrm{PR}=2.14,95 \%$ CI 1.33-3.44) as compared with RM census blocks.

\section{Discussion}

Our results indicate that inequities exist in the availability of food stores of predominantly African American and Latino census blocks as compared with racially mixed census blocks all within the minority, low-income neighbourhood of East Harlem, New York. Our findings are supported by other researchers who have reported that predominantly African American neighbourhoods have lower supermarket availability at both the census tract level and the zip code level ${ }^{16,18,26}$. Consistent with 
Table 1 Characteristics of census blocks by racial predominance

\begin{tabular}{|c|c|c|c|c|}
\hline & $\begin{array}{l}75 \% \text { African American } \\
\quad(N=17)\end{array}$ & $\begin{array}{l}75 \% \text { Latino } \\
(N=34)\end{array}$ & $\begin{array}{l}75 \% \text { racially mixed } \\
\quad(N=114)\end{array}$ & $\begin{array}{l}\text { All blocks } \\
(N=165)\end{array}$ \\
\hline Characteristic & Mean (SD) & Mean (SD) & Mean (SD) & Mean (SD) \\
\hline Population & $249(211)$ & $463(317)$ & $782(685)$ & $661(620)$ \\
\hline Area (sq km) & $0.022(0.024)$ & $0.014(0.004)$ & $0.020(0.013)$ & $0.019(0.013)$ \\
\hline Population density (persons/sq km) & $20006(17394)$ & $32129(18511)$ & 53057 (125942) & $45339(105695)$ \\
\hline Median gross rent* (\$US per month) & $470(221)$ & $506(269)$ & $535(315)$ & $522(298)$ \\
\hline \multirow{2}{*}{$\begin{array}{l}\text { Median household income* (\$US per } \\
\text { annum) }\end{array}$} & $23261(12085)$ & $20058(12275)$ & $26958(19872)$ & $25155(18189)$ \\
\hline & $n(\%)$ & $n(\%)$ & $n(\%)$ & $n(\%)$ \\
\hline Census blocks with no food stores & $13(76.47)$ & $5(14.71)$ & $46(40.35)$ & $64(38.79)$ \\
\hline
\end{tabular}

$\mathrm{SD}$ - standard deviation.

*Imputed values.

Table 2 Income- and population density-adjusted* prevalence ratios for food store availability by race/ethnicity of census blocks

\begin{tabular}{|c|c|c|c|c|c|c|c|c|c|}
\hline \multirow[b]{2}{*}{ Industry group } & \multicolumn{3}{|c|}{$75 \%$ African American $(N=17)$} & \multicolumn{3}{|c|}{$75 \%$ Latino $(N=34)$} & \multicolumn{3}{|c|}{$75 \%$ racially mixed $(N=114)$} \\
\hline & $n$ & $\mathrm{P}$ & $\mathrm{PR}(95 \% \mathrm{Cl})$ & $n$ & $P$ & PR $(95 \% \mathrm{Cl})$ & $n$ & $P$ & PR $(95 \% \mathrm{Cl})$ \\
\hline \multicolumn{10}{|l|}{ Food stores } \\
\hline Supermarkets $(N=9)$ & 0 & 0 & - & 3 & 0.09 & $1.49(0.68-3.24)$ & 6 & 0.05 & 1.00 (referent) \\
\hline Grocery stores $(N=8)$ & 0 & 0 & - & 1 & 0.03 & $0.61(0.20-1.86)$ & 7 & 0.06 & 1.00 (referent) \\
\hline Convenience stores $(N=168)$ & 4 & 0.24 & $0.25(0.07-0.86)$ & 58 & 1.71 & $1.80(1.20-2.70)$ & 106 & 0.93 & 1.00 (referent) \\
\hline Specialty food stores $(N=34)$ & 1 & 0.06 & $0.42(0.07-2.45)$ & 18 & 0.53 & $3.74(2.06-7.15)$ & 15 & 0.13 & 1.00 (referent) \\
\hline \multicolumn{10}{|l|}{ Food service } \\
\hline Full-service restaurants $(N=56)$ & 1 & 0.06 & $0.19(0.02-1.41)$ & 19 & 0.56 & $1.87(1.04-3.38)$ & 36 & 0.32 & 1.00 (referent) \\
\hline Fast-food restaurants $(N=130)$ & 4 & 0.24 & $0.34(0.09-1.22)$ & 49 & 1.44 & $2.14(1.33-3.44)$ & 77 & 0.68 & 1.00 (referent) \\
\hline
\end{tabular}

$n$ - number of food stores or food service places; $\mathrm{P}$ - prevalence of food stores or food service places; $\mathrm{PR}$ - prevalence ratio; Cl - confidence interval.

${ }^{\star}$ All models adjusted for population density and median household income.

these reports, we found that predominantly African American census blocks were less likely to have food stores located most convenient to where a family resides as compared with the racially mixed census blocks. In fact, none of the predominantly African American census blocks in East Harlem had supermarkets or grocery stores and this relationship remained even after controlling for median income, median rent and population density. Moreover, African American census blocks had fewer convenience stores, the predominant food store type in East Harlem, as compared with racially mixed census blocks.

While several studies have noted the stark contrasts between African American neighbourhoods and predominantly Caucasian neighbourhoods, this is one of the few studies to examine the food availability of Latino census blocks. This study demonstrates that in East Harlem, New York, predominantly Latino census blocks have more food stores in general than racially mixed census blocks, a stark contrast to our findings in African American census blocks.

Obesity rates, defined by a body mass index of $30 \mathrm{~kg} \mathrm{~m}^{-2}$ or greater ( $\sim 30 \mathrm{lb}$ overweight), are similar for East Harlem minority residents: 34\% for African American residents and 33\% for Latino residents, in stark contrast to $18 \%$ for white residents ${ }^{30}$. Hence, further research is needed to examine how cultural factors specific to African Americans and Latinos influence behaviour-environment interactions and subsequent risk for obesity. These factors include stores utilised, frequency of food shopping, types of foods purchased, and consumption of meals prepared inside or outside the home. A study of restaurant and food shopping selections among Latino women in Southern California noted two trends ${ }^{31}$. Latino women living in the USA for a longer period reported frequent visits to fast-food restaurants, citing lower cost of food, proximity and options for children (both menu options and play space availability) as reasons why they preferred eating at fastfood restaurants. In contrast, single women, women with more people to feed and women with lower degrees of acculturation reported shopping regularly in food stores with less healthy options. The authors concluded that acculturation may influence whether Latinos are comfortable shopping in large supermarkets where ethnic foods are less likely to be found, possibly due to language barriers or perhaps due to concerns about cost. Since we are examining only community-level factors and not individual-level factors, it is beyond the scope of our study to suggest the implications of our findings with respect to diet and risk for obesity and obesity-related complications. However, this is the first step towards improving our understanding of how inequities in food availability play a 
role in disparities in health-related outcomes. We plan to further evaluate racial/ethnic differences in types of food stores and restaurants frequented by East Harlem families in order to determine whether density and proximity of food stores influence utilisation, dietary quality and subsequent risk for obesity. Further studies are needed in a diversity of settings (urban, suburban and rural) in varying racial/ethnic groups across all socio-economic demographics in order to deepen our understanding of how the local food environment shapes dietary behaviours.

There are several limitations to this study. First, we were interested in the food environment in closest proximity to where a family resides and of greatest convenience to the family. We did not consider adjacency, i.e. whether food stores were present on a neighbouring block to where a family resides. Still, it remains significant that not one of the African American census blocks, clustered geographically, had a supermarket or grocery store while Latino blocks had more food stores in general as compared with racially mixed blocks.

When studying the impact of the food environment on dietary quality, it is unclear what geographic boundaries are most relevant in urban, densely populated areas such as East Harlem, New York. We chose to examine the geographical unit representing the smallest shopping distance for residents. Existing studies have examined the food environment at the census tract level and at the zip code level ${ }^{26,32}$. One study examined the relationship between various measures of food store access and household fruit and vegetable use among participants in the Food Stamp Program ${ }^{33}$. Distance from home to food store was inversely associated with fruit use by households. Similar patterns were seen with vegetable use, although associations were not significant. This suggests that smaller geographic areas of analysis may be more relevant in low-income, minority communities, although how small a geographic area remains to be determined.

These findings have the potential to elucidate the mechanism by which neighbourhood-level factors influence behavioural patterns, dietary quality and subsequent risk for obesity and obesity-related health outcomes. Several reports have been published demonstrating the constraints in daily activities including food shopping that low-income families face due to transportation difficulties, thus suggesting that convenience is a factor that influences where a family shops ${ }^{34-36}$. Supermarkets often carry low-cost foods and offer a greater selection of fresh, healthy food items; yet African Americans are unlikely to have these food stores located on their block (at the census block level) as well as at the census tract and zip code level $^{26,32}$. This suggests that African Americans must travel further to shop at such stores and this may in part account for disparities in health outcomes.

This relationship is complex however. Predominantly Latino census blocks had more food stores of all types, yet Latinos are also at increased risk for obesity compared with their Caucasian counterparts. Further research is needed to fully elucidate the exact mechanism by which the local food environment influences shopping patterns and hence dietary quality.

Further limitations include use of a $75 \%$ threshold level for defining census blocks by race/ethnicity. Other studies have used more or less stringent thresholds and the method by which one defines racial/ethnic predominance may influence food store counts. Furthermore, in an in-depth examination of a single New York City neighbourhood, specifically East Harlem, we have contrasted African American and Latino census blocks with racially mixed census blocks. While it is uncommon to contrast minority groups with one another, it was interesting to find that disparities are seen in food store availability by race/ethnicity even in a single minority community.

This study supports previous work on the local food environment and the importance of considering food availability both in counselling families in the clinical setting and in the development of obesity-related public health interventions. Neighbourhood-level interventions that have already been adopted include elimination of soda machines from schools nationwide ${ }^{37}$, stocking lowfat milk and snack size packages of pre-sliced apples and carrots in New York City convenience stores/bodegas ${ }^{38,39}$, and eliminating trans fats from restaurants and fastfood chains in major cities in the USA ${ }^{40}$. These are all instances where policy enforced community-level changes that promote a healthier lifestyle. Many of the major successes in public health have required targeting both individual- and community-level changes, as seen in recent trends in smoking cessation and childhood lead poisoning. This is in keeping with the epidemiological triad, which stresses the need to target three points of a triad (the host, the agents and vector) and the environment, in order to eliminate an epidemic ${ }^{41}$. When applied to the obesity epidemic, it emphasises a need for both individual- and population-level approaches. In this way, it more clearly illustrates the role of health professionals, the food industry and government policy-makers in treatment and prevention strategies, including those aimed at modifying the obesogenic environment. Our findings suggest that existing policies on the siting of stores in minority neighbourhoods is one area that must be furthered explored. In order to reverse the alarming trend in obesity in the USA we must begin to think about community-level changes that promote healthier lifestyles.

\section{Conclusions}

In examining food store availability by African American and Latino race/ethnicity at the census block level, we found that inequities exist in food store availability within 
the inner-city community of East Harlem, New York. These findings were independent of median income, median rent and population density. This has potential implications for racial/ethnic differences in dietary quality and associated health outcomes including obesity and obesity-related disorders such as diabetes, cardiovascular health and mental health. A better understanding of how neighbourhood-level factors influence dietary quality is essential to (1) inform interventions and guide evidencebased policy changes that may reduce obesity in predominately minority and urban communities and (2) ultimately improve the state of the environment and the health of children, families and communities at large.

\section{Acknowledgements}

This work was supported by the National Institute of Environmental Health Sciences (NIEHS) Grant \#2P01ES009584 and the Environmental Protection Agency (EPA) Grant \#R827039 and the Mount Sinai Pediatric Environmental Health Specialty Unit (PEHSU) Grant \#U50/ATU300014. Dr Moreland was supported in part by the National Institutes of Environmental Health Sciences Grant \#R25ES14315 under the 'Environmental Justice: Partnerships for Communication' program. Cherita Raines and Jessica Kobil were supported respectively by the Center for Multicultural Affairs Summer Health Services Research Program and the Patricia S Levinson Summer Fellowship. We are grateful to our collaborators and community partners, especially Susan Resnick at the New York City Department of Health and Mental Hygiene for her GIS (Geographic Information Systems) expertise including creation of the map found in this paper. Special thanks to the Community Advisory Board members who reviewed this paper: Mr Johnny Rivera, Ms Marge Ramirez, Dr Anjali Talwalkar and Dr Mary Wolff.

\section{References}

1 Ogden CL, Carroll MD, Curtin LR, McDowell MA, Tabak CJ, Flegal KM. Prevalence of overweight and obesity in the United States, 1999-2004. JAMA: Journal of the American Medical Association 2006; 295: 1549-55.

2 Galvez MP, Frieden TR, Landrigan PJ. Obesity in the 21st century. Environmental Health Perspectives 2003; 111: A684-5.

3 New York City Department of Mental Health Hygiene. Obesity begins early: findings among elementary school children in New York City. NYC Vital Signs 2003; 2: 1-2. Also available at http://www.nyc.gov/html/doh/pdf/ survey/survey-2003childobesity.pdf. Accessed 6 December 2004.

4 Booth KM, Pinkston MM, Poston WS. Obesity and the built environment. Journal of the American Dietetic Association 2005; 105: S110-17.

5 Dehghan M, Akhtar-Danesh N, Merchant AT. Childhood obesity, prevalence and prevention. Nutrition Journal 2005; 4: 24 .
6 Carter MA, Swinburn B. Measuring the 'obesogenic' food environment in New Zealand primary schools. Health Promotion International 2004; 19: 15-20.

7 Wakefield J. Fighting obesity through the built environment. Environmental Health Perspectives 2004; 112: A616-18.

8 Cummins SK, Jackson RJ. The built environment and children's health. Pediatric Clinics of North America 2001; 48: 1241-52.

9 Davison KK, Birch LL. Childhood overweight: a contextual model and recommendations for future research. Obesity Reviews 2001; 2: 159-71.

10 Hill JO, Wyatt HR, Melanson EL. Genetic and environmental contributions to obesity. Medical Clinics of North America 2000; 84: 333-46.

11 Roccini AP. Childhood obesty and a diabetes epidemic. New England Journal of Medicine 2002; 346: 854-5.

12 Diez Roux AV, Merkin SS, Arnett D, Chambless L, Massing $\mathrm{M}$, Nieto FJ, et al. Neighborhood of residence and incidence of coronary heart disease. New England Journal of Medicine 2001; 345: 99-106.

13 McGrath JJ, Matthews KA, Brady SS. Individual versus neighborhood socioeconomic status and race as predictors of adolescent ambulatory blood pressure and heart rate. Social Science \& Medicine 2006; 63: 1442-53.

14 Lewis LB, Sloane DC, Nascimento LM, Diamant AL, Guinyard JJ, Yancey AK, et al.; REACH Coalition of the African Americans Building a Legacy of Health Project. African Americans' access to healthy food options in south Los Angeles restaurants. American Journal of Public Health 2005; 95: 668-73.

15 Zenk SN, Schulz AJ, Israel BA, James SA, Bao S, Wilson ML. Neighborhood racial composition, neighborhood poverty, and the spatial accessibility of supermarkets in metropolitan Detroit. American Journal of Public Health 2005; 95: 660-667.

16 Moore LV, Diez Roux AV. Associations of neighborhood characteristics with the location and type of food stores. American Journal of Public Health 2006; 96: 325-31.

17 Morland K, Wing S, Diez Roux A, Poole C. Neighborhood characteristics associated with the location of food stores and food service places. American Journal of Preventive Medicine 2002; 22: 23-9.

18 Powell LM, Slater S, Mirtcheva D, Bao Y, Chaloupka FJ. Food store availability and neighborhood characteristics in the United States. Preventive Medicine 2007; 44: 189-195.

19 Block JP, Scribner RA, DeSalvo KB. Fast food, race/ethnicity, and income: a geographic analysis. American Journal of Preventive Medicine 2004; 27: 211-17.

20 French SA. Public health strategies for dietary change: schools and workplaces. Journal of Nutrition 2005; 135: 910-12.

21 Macdonald L, Cummins S, Macintyre S. Neighbourhood fast food environment and area deprivation - substitution or concentration? Appetite 2007; 41: 251-4.

22 Horowitz CR, Colson KA, Hebert PL, Lancaster K. Barriers to buying healthy foods for people with diabetes: evidence of environmental disparities. American Journal of Public Health 2004; 94: 1549-54.

23 Brownell KD. Fast food and obesity in children. Pediatrics 2004; 113: 132.

24 Sallis JF, Nader PR, Rupp JW, Atkins CJ, Wilson WC. San Diego surveyed for heart-healthy foods and exercise facilities. Public Health Reports 1986; 101: 216-19.

25 Morland K, Wing S, Diez Roux A. The contextual effect of the local food environment on residents' diets: The Atherosclerosis Risk in Communities Study. American Journal of Public Health 2002; 92: 1761-7. 
26 Morland K, Diez Roux AV, Wing S. Supermarkets, other food stores, and obesity: The Atherosclerosis Risk in Communities Study. American Journal of Preventive Medicine 2006; 30: 333-9.

27 Cummins S, Petticrew M, Sparks L, Findlay A. Large scale food retail interventions and diet. British Medical Journal 2005; 330: 683-4.

28 Allison PD. Missing Data. Thousand Oaks, CA: Sage Publications, 2001

29 Rosner B. Fundamentals of Biostatistics. New York: Duxbury Press, 1995.

30 Olson EC, VanWye G, Kerker B, Thorpe L, Frieden TR. Take Care East Harlem [online], 2006. Available at http:// www.nyc.gov/html/doh/downloads/pdf/data/2006chp-303. pdf. Accessed 3 May 2007.

31 Ayala GX, Mueller K, Lopez-Madurga E, Campbell NR, Elder JP. Restaurant and food shopping selections among Latino women in Southern California. Journal of the American Dietetic Association 2005; 105: 38-45.

32 Sturm R, Datar A. Body mass index in elementary school children, metropolitan area food prices and food outlet density. Public Health 2005; 119: 1059-68.

33 Rose D, Richards R. Food store access and household fruit and vegetable use among participants in the US Food Stamp Program. Public Health Nutrition 2004; 7: 1081-8.

34 Murakami E, Young J. Daily travel by persons with low income. Paper presented at the NPTS Symposium, Bethesda,
MD, 29-31 October 1997. Available at http://nhts.ornl.gov/ 1995/Doc/LowInc.pdf. Accessed 15 August 2007.

35 Clifton KJ. Mobility strategies and food shopping for low-income families: a case study. Journal of Planning Education and Research 2004; 23: 402-13.

36 Food Marketing Institute. The African American Grocery Shopper 2000. Washington, DC: Food Marketing Institute, 2000.

37 Newman M. Soda distributors to end most school sales. New York Times, 3 May 2006.

38 New York City Department of Health and Mental Hygiene. Moooove to 1\% milk project [online], 19 January 2006. Available at http://www.nyc.gov/html/doh/html/dpho/dphomoove.shtml.Accessed 9 January 2007.

39 New York City Department of Health and Mental Hygiene. Move to fruits and vegetables [online], 7 December 2006. Available at http://www.nyc.gov/html/doh/html/dpho/ dpho-move-fruits-vegetables.shtml. Accessed 9 January 2007.

40 New York City Department of Health and Mental Hygiene. Notice of adoption of an amendment (81.08) to article 81 of the New York City Health Code [online], 2006. Available at http://www.nyc.gov/html/ doh/downloads/pdf/public/notice-adoption-hc-art81-08.pdf. Accessed 9 January 2007.

41 Egger G, Swinburn B, Rossner S. Dusting off the epidemiological triad: could it work with obesity? Obesity Reviews 2003; 4: 115-19. 